\title{
PRENATAL SYPHILIS, WITH A PLEA FOR ITS STUDY AND PREVENTION *
}

\author{
JOHN A. KOLMER, M.D., DR.P.H., M.Sc. (HoN.)
}

Professor of Pathology and Bacteriology in the Graduate School of Medicine of the University of Pennsylvania; Head of the Department of Pathology in the Dermatological Research

Laboratories of Philadelphia

PHILADELPHIA

Recent events, and particularly the mobilization and demobilization of troops, has greatly renewed interest in the venereal diseases and aroused considerable concern by reason of their already wide distribution in civilian populations and the danger of further dissemination under existing conditions. Federal, state and municipal health authorities are generally aroused to the dangers of the situation, and are taking steps calculated to limit the spread of venereal diseases, and especially syphilis, and to facilitate their diagnosis and treatment. In this movement all physicians cannot fail to have an interest, and in choosing a subject for this address, I thought the time opportune for bringing before you the necessity of deeper clinical and immunologic study of prenatal syphilis and a consideration of ways and means for reducing the incidence of this disease and thereby reducing infant mortality in general, as well as entering into the general movement against the menace of syphilis.

Excellent reviews on the prevalence of syphilis have been published recently by Vedder ${ }^{1}$ and by Stokes; ${ }^{2}$ statistics indicate quite clearly the wide dissemination of this disease. Vedder estimates that from 10 to 28 per cent. of men from the class of unskilled labor and the trades, varying in age from 18 to 40 years, are syphilitic, as well as from 2 to 10 per cent. of men of better education. Among "presumably healthy young women, the percentage of syphilitic infections fluctuates between 2 and 20 per cent., depending on age, marital condition, education and social status. The infection is rare among unmarried girls of good character, but is only too common among married women whose virtue is beyond challenge. As among men, the proportion of infections increases as we descend in the social

\footnotetext{
* Presidential address delivered before the Philadelphia Pediatric Society, January, 1919.

1. Vedder, E. B.: Syphilis and Public Health, Lea \& Febiger, Philadelphia and New York, 1918.

2. Stokes, J. H.: The Third White Plague, W. B. Saunders Co., Philadelphia. 1917.
} 
scale." Evidence indicates that syphilis is far more common among negroes than among whites, and that it is even more frequent among negro women than among negro men; Vedder estimates that the rates for the colored race are at least double those for the white race.

It has been estimated that at least 10 per cent. of all marriages involve a syphilitic individual, and when it is remembered that the disease may be transmitted to children by either parent, and particularly the mother, for an indefinite period, the necessity for obstetricians and pediatrists keeping constantly in mind the subject of prenatal syphilis can scarcely be over-emphasized. Jeans ${ }^{3}$ recently stated that at least 75 per cent. of all the offspring in a syphilitic family are infected, and 30 per cent. of pregnancies terminate in death at or before term. Thirty per cent. of all infants born alive in a syphilitic family are believed to die in infancy, which is double the normal rate for children in the same class. Only 17 per cent. of all pregnancies in syphilitic families result in living nonsyphilitic children that survive the period of infancy and probably 30 per cent. of clinically syphilitic infants die as a result of syphilis.

Estimates on the prevalence of congenital or prenatal syphilis have been largely based on studies with the Wassermann test; a number of surveys since 1912 have shown positive reactions among from 2 to 6 per cent. of children as met with in dispensaries and hospitals. Studies conducted among backward or mentally deficient and sick children have shown a higher percentage of positive reactions. Very probably about 5 per cent. of children encountered in hospital and dispensary practice will yield positive Wassermann reactions, and it would appear safe to assume an incidence of at least 5 per cent. for syphilis in our infant population, in so far as the disease can be detected by ordinary means.

Without entering into a discussion on ways and means for the prevention of syphilis by the regulation or suppression of vice and education of the individual, my plea is for a closer and deeper clinical and immunologic study of prenatal syphilis on the part of obstetricians and pediatrists. Very probably most can be done toward checking the spread of syphilis, and particularly its transmission to offspring, by subjecting prospective and potential parents to clinical, and especially immunologic, examinations for syphilis, and affording adequate treatment within the means of all, including the poorest of persons, seeking medical aid in our dispensaries.

That prenatal clinics are proving of great value in the conservation not only of infant lives, but those of mothers as well, is now generally

3. Jeans, P. C.: Syphilis and Its Relation to Infant Mortality, Am. J. Syphilis 3:114 (Jan.) 1919; also abstr. in J. A. M. A. 71:2101 (Dec. 21) 1918. 
accepted; I regret that many - probably the majority - of obstetric clinics connected with our teaching institutions neglect the unborn child, being content to register the prospective mother, calculate the probable date of delivery and ascertain the dimensions of the pelvis and position of the fetus. I would urge on all such clinics and on all practitioners practicing obstetrics, the particular study of prospective fathers and mothers for historical, clinical and immunologic evidences of syphilis. This, for obvious reasons, may be difficult and indeed impossible in private practice, but in dispensaries few women will object to an examination of the blood for the Wassermann test if properly handled. An effort should also be made to examine the blood of the prospective father as well, and while this may not be possible on a large scale, it is facilitated by the aid of a social service department.

It has been stated that a man ceases to be infectious within from two to five years after contracting syphilis, depending on the thoroughness of treatment, but that a woman may transmit the disease for an indefinite period; this is probably fallacious teaching in so far as the infectiousness of men is concerned. Fournier, ${ }^{4}$ for example, in a study of 142 men who contracted syphilis prior to marriage and infected their wives, found that twenty-eight, or about 20 per cent., were known to have been syphilitic for from five and one half to eighteen years.

Certainly it would appear advisable, at least, to test the blood of prospective mothers and fathers for serologic evidences of syphilis, and if found positive, provide the means for adequate treatment. In this connection I may state that the Wassermann test is not too delicate, but very probably not delicate enough, and that even with the cooperation of a skilled and trustworthy serologist, a certain percentage of syphilitics will escape detection. A negative reaction, therefore, does not exclude syphilis, because the majority of syphilitic women are in the latent stages of the disease in which the complement fixation test is particularly prone to yield a negative result. The same is true of congenital syphilis, to which further reference will be made. I believe, therefore, in the employment of as delicate a complement fixation technic as is consistent with practical specificity, and that this end is best obtained by the use of cholesterolized extracts for antigens; also that an unmistakably positive reaction may be taken as evidence of the existence of syphilis and an indication for specific treatment.

Furthermore, I believe that it is proper to regard all children as probably syphilitic when born of parents one or both of whom react positively to the Wassermann test, even though both child and parents

4. Fournier, A.: La Syphilis der honnetes femmes, Bull. d. l'Acad. d méd. 66: 190,1906 . 
are clinically free of the disease; congenital syphilis may manifest itself in so many different ways that the usual clinical picture carried in the minds of the majority of physicians, namely, the child presenting the appearance of "the little old man with a cold in the head" and blebs on the skin, serves for the clinical diagnosis of but a small percentage. As is well known, there may be no discernible lesions and symptoms, and all immunologic tests, such as the Wassermann and the luetin tests, may be negative because so many prenatal infections are with treponemas of attenuated virulence inducing a latent form of the disease, which may not spring into renewed activity for several years after birth. Inasmuch as all evidence indicates that a persistently positive Wassermann reaction means the presence of living treponemas in the body even in the absence of discernible lesions and symptoms, and since the possibility of transmission of these to offspring always exists and particularly from the Wassermann positive mother, I believe that the physician does well to regard with suspicion the offspring of such parents and even to institute specific treatment as a precautionary measure, and especially if such children are manifestly below par in weight and nutrition.

For the study of the incidence of prenatal or congenital syphilis, the Wassermann test alone with the blood of the child is of limited value and cannot be relied on to give complete information. As previously stated, it is prone to yield an erroneous negative result in latent congenital syphilis, although invariably positive in active cases with lesions and symptoms. In my experience, the luetin skin anaphylactic test is of particular value in the immunologic diagnosis of congenital syphilis and an unmistakably positive reaction may be accepted as evidence of syphilis even though the Wassermann test is negative. Such studies should start with the parents and embrace at least the Wassermann test with the blood of the mother and, if possible, of the father, along with judicious inquiries into the previous histories of both as concerns syphilis. Children should be subjected not only to the Wassermann and luetin tests, but to thorough clinical studies, the latter being carried out under best conditions, not by one physician, but, if possible, by several specialists working in cooperation, and particularly an ophthalmologist, a neurologist and psychiatrist and a roentgenologist, inasmuch as syphilis may manifest itself in special organs and thereby escape detection by the general practitioner and pediatrist.

While such studies would prove of great value in emphasizing the importance of syphilis to the individual and the state, and in relation to the important subject of infant mortality, its chief practical object would be lost unless a serious attempt were made to afford adequate treatment for all syphilitics, rich and poor alike. There appears but 
one way to reduce the mortality and menace of prenatal syphilis, and that is by the treatment of the prospective and potential syphilitic parent or parents until the danger of transmission is greatly reduced or permanently removed. While health officials and moralists are very properly endeavoring to combat the disease by the eradication and suppression of prostitution and by education of the individual to "mold the desire to live in accordance with the laws of nature," the physician may logically assume that systematic treatment is the only method for reducing the number of venereal infections, and particularly the number of syphilitic infections. Moreover, as stated by Vedder, systematic treatment is the only hopeful and available method for several reasons; it is the one method on which everyone, whatever his or her moral beliefs, can agree, for the morality of the healing of the sick is above suspicion, and no one will challenge the morality of the attempt to treat all venereal diseases. From the sanitary point of view, the treatment of the infected is, perhaps, the most efficacious single method that can be applied, because if all infected individuals are rendered incapable of transmitting their infection the disease will disappear.

I hope that this brief review of so important a subject as congenital syphilis will at least serve to arouse renewed interest on the part of all physicians concerned in the prenatal and the postnatal care of children as obstetricians and pediatricians; it is the disease that should draw both obstetrician and pediatrist into closer professional cooperation, and constitutes an important reason for enlisting the services of the pediatrist in the care of the child before its birth, instead of being turned over to him some weeks or months after this event. The obstetrician alone, and the prenatal clinic, can do most in lowering the high but really unknown percentage of intrauterine deaths of human beings who never had a chance for survival, by adequate treatment of the unfortunate parents; the pediatrician can aid in this work if he is called in time and given an opportunity, and he may do much toward lowering infant mortality by bearing in mind the wide dissemination of syphilis among persons of marriageable age in both sexes, and the imminent danger of transmission to their offspring. 